NASA/TM-2000-210363

\title{
Lessons Learned During Solutions of Multidisciplinary Design Optimization Problems
}

Surya N. Patnaik

Ohio Aerospace Institute, Brook Park, Ohio

Rula M. Coroneos, Dale A. Hopkins, and Thomas M. Lavelle Glenn Research Center, Cleveland, Ohio 
Since its founding, NASA has been dedicated to the advancement of aeronautics and space science. The NASA Scientific and Technical Information (STI) Program Office plays a key part in helping NASA maintain this important role.

The NASA STI Program Office is operated by Langley Research Center, the Lead Center for NASA's scientific and technical information. The NASA STI Program Office provides access to the NASA STI Database, the largest collection of aeronautical and space science STI in the world. The Program Office is also NASA's institutional mechanism for disseminating the results of its research and development activities. These results are published by NASA in the NASA STI Report Series, which includes the following report types:

- $\quad$ TECHNICAL PUBLICATION. Reports of completed research or a major significant phase of research that present the results of NASA programs and include extensive data or theoretical analysis. Includes compilations of significant scientific and technical data and information deemed to be of continuing reference value. NASA's counterpart of peerreviewed formal professional papers but has less stringent limitations on manuscript length and extent of graphic presentations.

- TECHNICAL MEMORANDUM. Scientific and technical findings that are preliminary or of specialized interest, e.g., quick release reports, working papers, and bibliographies that contain minimal annotation. Does not contain extensive analysis.

- CONTRACTOR REPORT. Scientific and technical findings by NASA-sponsored contractors and grantees.
- CONFERENCE PUBLICATION. Collected papers from scientific and technical conferences, symposia, seminars, or other meetings sponsored or cosponsored by NASA.

- SPECIAL PUBLICATION. Scientific, technical, or historical information from NASA programs, projects, and missions, often concerned with subjects having substantial public interest.

- TECHNICAL TRANSLATION. Englishlanguage translations of foreign scientific and technical material pertinent to NASA's mission.

Specialized services that complement the STI Program Office's diverse offerings include creating custom thesauri, building customized data bases, organizing and publishing research results ... even providing videos.

For more information about the NASA STI Program Office, see the following:

- Access the NASA STI Program Home Page at http://www.sti.nasa.gov

- E-mail your question via the Internet to help@sti.nasa.gov

- Fax your question to the NASA Access Help Desk at (301) 621-0134

- Telephone the NASA Access Help Desk at (301) 621-0390

- Write to:

NASA Access Help Desk

NASA Center for AeroSpace Information 7121 Standard Drive

Hanover, MD 21076 
NASA/TM-2000-210363

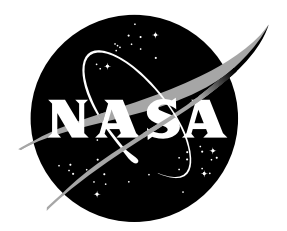

\section{Lessons Learned During Solutions of Multidisciplinary Design Optimization Problems}

Surya N. Patnaik

Ohio Aerospace Institute, Brook Park, Ohio

Rula M. Coroneos, Dale A. Hopkins, and Thomas M. Lavelle Glenn Research Center, Cleveland, Ohio

National Aeronautics and

Space Administration

Glenn Research Center 
Trade names or manufacturers' names are used in this report for identification only. This usage does not constitute an official endorsement, either expressed or implied, by the National Aeronautics and Space Administration.

Available from

NASA Center for Aerospace Information 7121 Standard Drive

Hanover, MD 21076

Price Code: A03
National Technical Information Service 5285 Port Royal Road Springfield, VA 22100 Price Code: A03 


\title{
Lessons Learned During Solutions of Multidisciplinary Design Optimization Problems
}

\author{
Surya N. Patnaik \\ Ohio Aerospace Institute \\ Brook Park, Ohio 44142 \\ Rula M. Coroneos, Dale A. Hopkins, and Thomas M. Lavelle \\ National Aeronautics and Space Administration \\ Glenn Research Center \\ Cleveland, Ohio 44135
}

\begin{abstract}
Optimization research at NASA Glenn Research Center has addressed the design of structures, aircraft and airbreathing propulsion engines. During solution of the multidisciplinary problems several issues were encountered. This paper lists four issues and discusses the strategies adapted for their resolution. (a) The optimization process can lead to an inefficient local solution. This deficiency was encountered during design of an engine component. The limitation was overcome through an augmentation of animation into optimization. (b) Optimum solutions obtained were infeasible for aircraft and airbreathing propulsion engine problems. Alleviation of this deficiency required a cascading of multiple algorithms. (c) Profile optimization of a beam produced an irregular shape. Engineering intuition restored the regular shape for the beam. (d) The solution obtained for a cylindrical shell by a subproblem strategy converged to a design that can be difficult to manufacture. Resolution of this issue remains a challenge. The issues and resolutions are illustrated through six problems: (1) design of an engine component, (2) synthesis of a subsonic aircraft, (3) operation optimization of a supersonic engine, (4) design of a wave-rotor-topping device, (5) profile optimization of a cantilever beam, and (6) design of a cylindrical shell. The combined effort of designers and researchers can bring the optimization method from academia to industry.
\end{abstract}

\section{Introduction}

Optimization research at NASA Glenn Research Center has addressed the structural design of airbreathing propulsion engines and Space Station components, aircraft synthesis, as well as performance improvement of the engines. The accumulated multidisciplinary design activity is collected under a testbed entitled COMETBOARDS (ref. 1). Several issues were encountered while generating solutions to the multidisciplinary problems. This paper lists four issues and presents the strategies that were employed for their resolutions. (a) The optimization process produced a local inefficient design for a rear divergent flap of a downstream mixing nozzle. An augmentation of animation improved the design. (b) Solutions obtained for aircraft and engine problems, using single optimization algorithm, encountered infeasibility even though the values of the merit function were in the vicinity of the correct solutions. The infeasibility was eliminated through a cascading of multiple algorithms. (c) The shape optimization of a beam produced an irregular shape. The regular shape could be restored through engineering intuition. (d) For a cylindrical shell, the 
subproblem solution strategy converged to local design that could be difficult to manufacture. Resolution of this issue is a challenge. This paper expounds upon the lessons learned in solving multidisciplinary problems with little emphasis on the algorithm or analysis method. The paper is divided into five subsequent sections. An outline to the testbed COMETBOARDS is given in section II. A description of the illustrative examples is given in section III. The next section describes the four issues: the local solution and animation, infeasibility and the cascade strategy, irregular design and intuition, and substructure solution and manufacturability. Discussions and conclusions are given in sections V and VI.

\section{COMETBOARDS Testbed}

The design optimization testbed COMETBOARDS can evaluate the performance of different optimization algorithms and analysis methods while solving a problem. It is a research testbed but not a commercial code. The acronym COMETBOARDS stands for "COMparative Evaluation TestBed of Optimization and Analysis Routines for the Design of Structures." The scope of the testbed has been expanded to include the design of structures, the synthesis of aircraft, the operation optimization of airbreathing propulsion engines. COMETBOARDS has three different analysis methods and one dozen optimization algorithms. It has a modular organization with a soft coupling feature, which allows quick integration of new or user-supplied analyzers and optimizers without any change to the source code. The COMETBOARDS code reads information from data files; formulates design as a sequence of subproblems, and generates the optimum solution. COMETBOARDS can be used to solve a large problem, definable through multiple disciplines, each of which can be further broken down into subproblems. Alternatively, it can improve an existing system by optimizing a small portion of a large problem. Other unique features of COMETBOARDS include design variable formulation, constraint formulation, subproblem strategy, global scaling technique, analysis approximation through neural network and linear regression method, use of sequential or parallel computational platforms, and so forth. The special features and unique strengths of COMETBOARDS assist convergence and reduce the amount of CPU time required to solve difficult optimization problems of the aerospace industry. COMETBOARDS has been successfully used to solve the structural design of the International Space Station components, the design of the nozzle components of an airbreathing engine, and airframe and engine synthesis for subsonic and supersonic aircraft, mixed flow turbofan engine, wave-rotor-topped engine, and so forth. The modular organization of COMETBOARDS is depicted in Figure 1. Brief descriptions of some of its modules follow.

Scaling and constraint formulation: A multidisciplinary design problem can have a distorted design space because its variables and constraints can vary over a wide range. For example, an engine thrust design variable, which is measured in kilopounds, is immensely different from its bypass ratio, which is a small number. Likewise, the landing velocity of an aircraft measured in knots and landing or takeoff field lengths measured in units of thousands of feet differ both in magnitude and in units of measure. This module provides a scheme to reduce the distortion by scaling the design variables, the objective function, and the constraints such that their relative magnitudes during optimization calculations are around unity. The constraints are reformulated to alleviate redundancy without affecting the problem definition. Constraint formulation alleviates redundancy and reduces their number (ref. 2). The cascade algorithm employs more than one optimizer to solve a complex design problem when individual mathematical programming methods experience difficulty (ref. 3). 
The module "Analyzers - Structure, Aircraft, Engine-Neural networks and Regression approximations" houses three different types of analysis methods. For structural analysis the methods available are: COSMIC NASTRAN (ref. 4), MSC/NASTRAN (ref. 5), MHOST (ref. 6), Analyze/Danalyze codes (ref. 7), and IFM/Analyzers (ref. 8). Aircraft analysis can use the FLOPS code (ref. 9). The NEPP code (ref. 10) is employed for airbreathing propulsion engine cycle analysis. Neural network (ref. 11) and regression techniques (ref. 12) can be employed for analysis approximation. A problem can utilize any one of three analyzers: (1) an original analyzer, for example FLOPS code, or one of the two derived analyzers based on (2) a neural network or (3) a regression approximation.

The module "Engine operations" in Figure 1 refers to the performance optimization of airbreathing propulsion engines for multiple operation points (ref. 13). "Aircraft synthesis" refers to the airframe and engine integration for subsonic and supersonic aircraft (ref. 3).

The module "Structural design—Subproblem strategy and Parallel computational environment" refers to design of structures through regular optimization or a subproblem strategy. This strategy is available in sequential and parallel computational environments (ref. 14). "Multiple disciplines" refers to the solution of a problem, which is defined through different disciplines. COMETBOARDS can accommodate several disciplines each of which can be further divided into subproblems. Subproblem strategy is an attempt to alleviate convergence difficulties that can be encountered during the solution of a large optimization problem. In this strategy the large problem is replaced by a sequence of overlapping modest subproblems. The solution to the large problem is obtained by repeating the solution to the set of subproblems until convergence is achieved.

Substructure strategy, a key module of COMETBOARDS, is further illustrated through the design of a cargo-bay support of the International Space Station. The support structure is fabricated out of four plates, a cluster of plates referred to as a box, and five beams, as shown in Figure 2. For the purpose of design, the support system was divided into four active and one passive substructures. The first substructure was the closed box (FGHKIJ) consisting of five plates. Its finite element model was obtained by discretizing it into 72 (QUAD4 ) shell elements. The second substructure was a trapezoidal plate (FHEC), and its finite element model had 37 shell elements. The third and fourth substructures were triangular plates (GHE and GHD) with 12 finite elements each. The fifth substructure contained the five connecting beams BD, BG, AD, AG, and AF. The beam designs were not changed. These passive variables did not participate in the design calculations but were retained during reanalysis. Two independent finite analysis codes LE_HOST and MSC/NASTRAN were used to verify the finite element model of the support structure. The finite element model with a total of 133 QUAD4 shell and 20 beam elements was considered adequate for design optimization because both analyzers produced an acceptable level of accuracy for stress, displacement, and frequency. The substructures were clustered next to obtain a set of subproblems. A subproblem contains a substructure along with some or all of its neighboring substructures. The four substructures were clustered to obtain the following four subproblems:

Subproblem 1: substructures 3 and 4

Subproblem 2: substructures 1 and 4

Subproblem 3: substructures 1 and 2

Subproblem 4: substructures 2 and 3

Notice the coupling between subproblems: substructure 1 is common to subproblems 2 and 3. Likewise, substructure 2 is common to subproblems 3 and 4, and so forth. Adequate coupling between substructures is required for convergence. Inappropriate coupling can increase the amount of computation and/or encounter convergence difficulties. At this time substructure coupling is decided intuitively. However, it may be possible to automate substructure coupling through the 
gradient scheme developed in reference 15. The COMETBOARDS testbed can optimize a system that can be defined in terms of 100 optimization subproblems (ref. 14).

In the module "Problem formulation and solution," information is read from data files, the design is cast as a sequence of optimization subproblems, and the solution is obtained.

The COMETBOARDS testbed is written in the Fortran 77 language except for the neural network algorithm, which is written in the $\mathrm{C}++$ language. The testbed is available in the Unix operating system in workstations and Cray computers.

\section{II.1 Optimization Algorithms in COMETBOARDS}

One dozen mathematical programming algorithms are available in COMETBOARDS. A list of the algorithms in no particular order follows.

(1) Method of feasible direction (FD) (ref. 16)

(2) Modified feasible direction method (mFD) (ref. 17)

(3) Reduced gradient method (RG) (ref. 18)

(4) Generalized reduced gradient method (GRG) (ref. 19)

(5) Sequence of unconstrained minimization technique (SUMT) (ref. 20)

(6) Sequential linear programming (SLP) (ref. 16)

(7) Sequential quadratic programming method (SQP) (ref. 21)

(8) IMSL optimization routine (IMSL) (ref. 22)

(9) NPSOL package of NAG library (NLPQ) (ref. 23)

(10) Sixteen different versions of optimality criteria methods (OC) (ref. 24)

(11) A genetic algorithm (GENMO) (ref. 25)

(12) Fully utilized design algorithm (FUD) (ref. 15)

Different algorithms employ different strategies to calculate the search direction and the step length. The comparative performance of the algorithms in solving a set of 45 problems is reported in reference 26. The performance of six algorithms in solving a set of medium and large structural problems is depicted in a bar chart in Figures 3(a) and 3(b), respectively. Examples with design variables in the range of 20 to 39 with about 200 behavior constraints are referred to as medium problems, see Figure 3(a). Examples with more than 40 independent design variables and several hundred constraints are referred to as large problems, see Figure 3(b). The success rate of different optimization algorithms for 10 large structural problems is also depicted in a Venn diagram in Figure 3(c). Cascade solutions for the problem are given in a table (see insert 3(e)). The success of an algorithm is represented by unity, which is the normalized value of the merit function, see Figures 3(a) and 3(b). A normalized value of less than unity (an infeasible solution) or greater than unity (an overdesign condition) represents underperformance. Most optimizers available in the testbed solved at least one-third of the examples, but none of the optimizers could successfully solve all the problems. Every structural problem could be solved by at least one of the six different optimization algorithms. However, even the most robust optimizer encountered difficulty in generating optimum solutions for aircraft and engine problems.

\section{Illustrative Examples}

For the purpose of illustration, we have selected six problems:

Problem 1-Structural design of an engine component.

Problem 2-Synthesis of a subsonic aircraft.

Problem 3-Operation optimization of a supersonic engine. 
Problem 4-Design of a wave-rotor-topping device.

Problem 5-Profile optimization of a cantilever beam.

Problem 6-Design of a cylindrical shell.

Augmentation of animation into optimization is illustrated through Problem 1. Problems 2, 3, and 4 illustrate the cascade strategy. Problem 5 addresses shape optimization. The subproblem solution strategy is illustrated through problem 6 . Brief definitions of the problems follow.

\section{III.1 Problem 1: Structural Design of an Engine Component}

A mixed-flow turbofan engine exhaust nozzle referred to as a "downstream mixing nozzle" for a High Speed Civil Transport aircraft to operate at a cruise speed of Mach 2.4 and in a range of 5000 nautical miles is shown in Figure 4(a). It is fabricated out of rear and forward divergent flaps, rear and forward sidewalls, bulkheads, duct extensions, six disk supports, and other components. The design complexity of the nozzle is increased with flight Mach number, pressure ratio, temperature gradient, dynamic response, and degradation of material properties at elevated temperature. The flap is made of Rene 125 material with a Young's modulus of 30.4 million psi, a Poisson ratio of 0.3 , a density of $0.308 \mathrm{lb} / \mathrm{in}^{3}$ and an allowable strength of $117 \mathrm{ksi}$. The flap shown in Figure 4(b) has a length of 96 in. and a width of 72 in. It is supported by two variable-depth edge beams with a maximum depth of 14 in. A grid with a spacing of 12 in. by 12 in. and a depth of 2 in. stiffens the flap. MHOST and MSC/NASTRAN analyzers were used for the static as well as the dynamic analyses of the flap. A finite element model with 5593 degrees of freedom and 946 QUAD4 elements was used for analysis because both methods produced acceptable values for stress, deformation, and frequency. For this problem, the thickness of the edge beams, stiffeners, and skin panel were considered as the design variables. The flap was designed for minimum weight for von Mises stress, local buckling, displacement, and frequency constraints. The problem had 946 stress and 946 instability constraints, as well as four displacements and one-frequency constraints.

\section{III.2 Problem 2: Synthesis of a Subsonic Aircraft}

The system synthesis capability of COMETBOARDS is illustrated through a subsonic aircraft to operate at Mach 0.85 cruise speed. Solution of this problem required a soft coupling of COMETBOARDS to NASA Langley's aircraft analysis code FLOPS. The FLOPS analyzer encompasses several disciplines: weight estimation, aerodynamic analysis, engine cycle analysis, propulsion data interpolation, mission performance, airfield length requirement, noise footprint calculation, and cost estimation (refs. 27, 28, and 29). The objective of the synthesis problem was to determine an optimum airframe-engine design combination for a set of active design variables under specified engine and aircraft behavior parameters to minimize a composite merit function that could be generated as a linear combination of weight, mission fuel, lift-to-drag ratio, and $\mathrm{NO}_{\mathrm{x}}$ emission. The design variables considered were engine thrust, wing area, engine design point turbine entry temperature, overall pressure ratio, bypass ratio, and fan pressure ratio. Constraints were imposed on mixed approach climb thrust, second segment climb thrust, landing approach velocity, takeoff field length, jet velocity, and compressor discharge temperature. For the subsonic aircraft model, the gross takeoff weight was considered as the merit function.

\section{III.3 Problem 3: Operation Optimization of a Supersonic Engine}

The operation optimization of airbreathing propulsion supersonic engine required a soft coupling of the analyzer NEPP, the NASA Engine Performance Program, to the optimization testbed COMETBOARDS. The engine-cycle NEPP code can configure and analyze almost any 
type of gas turbine engine that can be generated through the interconnection of a set of standard physical components such as propellers, inlets, combustors, compressors, turbines, heat exchangers, flow splitters, nozzles, and others. An engine can be designed for different types of hydrocarbon jet fuels, cryogenic fuel, and slurries. For their thermodynamic analysis, built-in curve fits generated from empirical results have been incorporated into the NEPP code. A description of the NEPP code with typical input files for a set of engine configurations can be found in references 30 and 31 .

The engine operation optimization problem, with its associated design variables (such as the engine shaft speed, the wave-rotor speed, the flow area, the geometrical parameters of the ducts, etc.) and constraints (imposed on pressure ratios, surge margins, temperature limits, and entrance Mach number, etc.) was cast as a sequence of nonlinear optimization subproblems with thrust as the merit function. Engine operation design became a sequence of interdependent problems, or one optimization subproblem for each operating point. The optimization process typically adjusted a few engine parameters. The difficulty in the engine problem did not lie with the number of active design variables, but it was associated with its multiple operating-point character, constraint validity ranges, and the iterative nature of engine cycle analysis. The most reliable individual optimization algorithm available in COMETBOARDS could not produce a satisfactory feasible optimum solution for this engine problem because of the large number of operation points in the flight envelope, the diversity of the constraint types, and the overall distortion of the design space. However, COMETBOARDS' unique features - which included a cascade strategy, variable and constraint formulations, and scaling devised especially for difficult multidisciplinary applicationssuccessfully optimized the performance of subsonic and supersonic engine concepts. Even when started from different design points, the combined COMETBOARDS and NEPP codes converged to about the same global optimum solution. This reliable and robust design tool eliminated manual intervention in the design of the airbreathing propulsion engines and eased the cycle analysis procedures.

Engine design is illustrated through a supersonic Mixed-Flow Turbofan Engine (MFTF) problem. It was configured with 15 components and was designed for a flight envelope with 122 operating points. The design required the solution of a sequence of 122 optimization subproblems. The objective was to maximize the net thrust of the supersonic engine at each operating point, accounting for an installation drag. Each subproblem had 3 independent design variables and 22 behavior constraints.

\section{III.4 Problem 4: Design of a Wave-Rotor-Topping Device}

A high bypass-ratio subsonic wave-rotor topped turbofan engine is made of 16 components that are mounted on two shafts with 21 flow stations. It was modeled with standard components that include an inlet and a splitter, then branching off to a compressor, a duct, and a nozzle. The main flow proceeded through a fan, a duct, a high-pressure compressor, a duct, a high-pressure turbine, a low-pressure turbine, a duct, and a nozzle. The components mounted on the first shaft included the fan, the compressor along the secondary flow branch, the low-pressure turbine, and a load. The second shaft carried the high-pressure compressor along the main flow, the high-pressure turbine and a load. The four-port wave-rotor (with burner inlet and exhaust, compressor inlet, and turbine exhaust), was located between the high-pressure compressor and the high-pressure turbine. The engine operating condition was specified by a 47-mission flight envelope, with altitude in the range (sea level to $40000 \mathrm{ft}$ ) and speed between (0.0 to 0.85) Mach. To examine the benefits that accrue from the wave-rotor device, the engine was optimized considering several of its baseline variables and constraints, not explicitly associated with the wave-rotor, as passive. The design 
objective was to maximize the net engine thrust at each of the 47 operating points. It had two design variables: heat added to the wave-rotor and the wave-rotor speed. Its 16 behavior constraints included the corrected speed ratio for the compressor and the fan, the unmixed wave-rotor temperature, the surge margin on the compressor, and the fan pressure ratio for the turbine.

\section{III.5 Problem 5: Cantilever Beam}

Calculation of an optimum profile or depth along the length is illustrated considering the cantilever beam shown in Figure 5. The beam is made of aluminum with a Young's modulus $\mathrm{E}=10 \times 10^{6}$ psi, a Poisson's ratio $v=0.3$, and a weight density $\rho=0.1 \mathrm{lb} / \mathrm{in}{ }^{3}$ It is $240 \mathrm{in}$. long and 6 in. deep. The beam weight was the merit function and stress and displacement were its behavior constraints. For the purpose of analysis, the beam was modeled with six 20-node-hexahedral elements of the IFM/Analyzers code (ref. 32). The finite element model with 160 displacement degrees-of-freedom was used for the analysis model because it adequately predicted the stress and displacement responses of the beam. The profile optimization problem had nine depth design variables, and its nine constraints included eight stress and one displacement limitations.

\section{III.6 Problem 6: Cylindrical Shell}

A cylindrical shell with rigid diagrams under two line loads is shown in Figure 6. It is made of steel with a Young's modulus $\mathrm{E}=30 \times 10^{6} \mathrm{psi}$, a Poisson's ratio $v=0.3$, and a weight density $\rho=0.289$ $\mathrm{lb} / \mathrm{in}^{3}$. It has a radius of $100 \mathrm{in}$. and length of $200 \mathrm{in}$. Because of symmetry, only one-eighth of the structure was considered for design. A finite element model with 100 QUAD4 elements of the MHOST analyzer was considered adequate to predict its response. Its design was cast as an optimization problem with weight as the objective function and constraints were imposed on stress and displacement. The thickness of the cylinder along its length and circumference were considered as design variables through a profiled depth link factor to provide a heavier design under the load. The oneeighth shell model was divided into four substructures along its length. The substructures were clustered to obtain three and four subproblems for sequential and parallel computations, respectively. An additional fourth subproblem was required to avoid convergence difficulty in parallel calculations.

\section{Issues in Multidisciplinary Design Optimization}

The four issues: (a) local solution and animation, (b) infeasibility and cascade strategy, (c) irregular design and intuition, and (d) substructure solution and manufacturability are addressed in this section.

\section{IV. (a) Local Solution and Animation}

The design of the flap or Problem 1, which is depicted in Figure 4(b), was obtained using three optimization algorithms. All three methods produced the same optimum weight of $1448.2 \mathrm{lb}$. At the optimum, the frequency at $40 \mathrm{~Hz}$ and displacement at 1 in. were the active constraints. Stress and local instability were passive constraints. Its animation at the $40 \mathrm{~Hz}$ frequency was examined, and one frame is depicted in Figure 4(c). The animation exhibited a local frequency condition. The edge beams vibrated with significant amplitude, while the response of the rest of the structure was insignificant. In other words, only a small part of the structure carried a major portion of the load. In this design, the edge-beams became more failure prone than other parts of the structure. 
The configuration of the flap was modified through an examination of the animation of a series of designs. The final modified configuration was obtained by increasing the depth of a single edge stiffener to 6 in. from its original 3-in. depth. This configuration was optimized. The increase in the material for this stiffener was compensated for by a reduction in the thickness of the edge beam by 58 percent between the two configurations. The dynamic animation of the flap and the von Mises stress distribution are shown in Figures 4(d) and 4(e), respectively. The structure vibrated in a breathing type of mode, or the entire flap responded as a single unit. The optimum design also displayed a full stress condition for a major portion of the flap as shown in Figure 4(e). The optimum weight at $1204.7 \mathrm{lb}$. was 20 percent lighter than the original configuration. Animationassisted optimization reduced the weight and improved the overall design of the flap.

\section{IV. (b) Infeasibility and Cascade Strategy}

Individual optimization algorithms encountered difficulty in generating solutions to aircraft and engine problems. A useful strategy that combined the strength of more than one optimizer was conceived. This cascade strategy, using a number of optimization algorithms, one followed by another in a specified sequence, was found to be superior to the component optimizers, see Figure 3(d). The cascade algorithm was employed to solve the 10 large structural problems referenced in Section II.1. The success rate of the cascade strategy and the individual algorithms is shown in Figures 3(c) and 3(e). The cascade strategy solved all 10 problems.

Cascade solutions to the subsonic aircraft, the supersonic mixed-flow turbofan engine, and the subsonic wave-rotor-topped engine are shown in Figure 7. The subsonic aircraft system design problem was solved using a three-optimizer cascade algorithm: optimizer 1, followed by optimizer 2 and optimizer 1 again. The cascade solution, along with solutions obtained from individual algorithms, is depicted in Figure 7 and Table I.

Optimizer 1, when used alone, converged to a heavy infeasible solution at $202005 \mathrm{lb}$ for the aircraft weight see Figure 7(a). Likewise, optimizer 2 alone also produced a heavy design at 202854 lb, see Figure 7(b). Optimizer 1 required a takeoff field length of $6282 \mathrm{ft}$ against an available 6000-ft runway. Optimizer 2 overestimated the excess fuel requirement at $8150 \mathrm{gal}$ against a desired amount of 5000 gallons. The convergence rate of the two algorithms differed producing solutions that were 1 percent and 2 percent overweight, respectively, for the two algorithms, see Figures 7(a) and 7(b). The two solutions, although close to the optimum, were not attractive to industry because they violated the safety margins. A cascade algorithm created from the same two optimizers (optimizer 1 - optimizer 2 - optimizer 1) successfully solved the problem with a feasible optimum solution at $199818 \mathrm{lb}$ for the aircraft weight, see Figure 7(c).

Solution of the mixed-flow supersonic and wave-rotor-topped subsonic engines also required the cascade strategy. A two-optimizer cascade, (optimizer 3 followed by optimizer 2) successfully solved the supersonic engine problem, see Figure 7(d). The solution to the wave-rotorenhanced subsonic engine, see Figure 7(e), required a three-optimizer cascade algorithm: optimizer 1 followed by optimizer 2 and optimizer 1 again.

Aircraft (FLOPS) and engine (NEPP) analyzers are nonlinear codes that incorporate multiple disciplines. The analysis assumptions, dependent on altitude, Mach number, and engine power setting, can be challenged. The Newton-Raphson iterations during "engine-balancing" may not converge, leading to an engine "stall condition" with zero thrust, or to the NEPP code producing a $\mathrm{NaN}$ (not a number) for some constraints. A single optimization algorithm can terminate abruptly,

or hit a constraint boundary without any improvement to the merit function. To overcome the difficulties in aircraft and engine analysis codes we employed two competing approximators: linear 
regression and neural network methods. Even then, the cascade algorithm was required because individual algorithms encountered difficulty (ref. 13). The nature of engine and aircraft problems required the strength of multiple algorithms or the cascade strategy even with the analysis approximators, which however, was not expected.

\section{IV.(c) Irregular Design and Intuition}

The profile optimization of the cantilever beam, or Problem 5, was attempted with uniform upper and lower bounds for the design variables at $0.5 \mathrm{in}$. and $15 \mathrm{in}$., respectively, see Table II. The optimization problem was solved using optimizer 4. The solution obtained is shown in Figure 5 and Table II. The optimum weight was $1697.5 \mathrm{lb}$, and the root stress was the only active constraint. An odd-shaped profile shown in Figure 5 was obtained. The profile was peculiar because the free end, corresponding to a zero stress condition, had a depth of 5.14 in. instead of an anticipated lower bound depth of 0.5 in. The optimum solution most likely challenged linear structural analysis assumptions, and the optimization iterations encountered difficulties. The situation did not improve when a different optimization algorithm or a cascade strategy was employed. The problem was solved successfully with manual intervention. Instead of uniform upper or lower bounds and a single optimization algorithm, the design was cast as a sequence of subproblems. Upper and lower bounds and initial design— through engineering intuition—were progressively changed for the subproblems. This procedure produced a converged solution that is shown in Figure 5. It had the same minimum weight of $1697.5 \mathrm{lb}$, which was identical to the odd-shaped design. Its root stress and tip displacement were the active constraints. For this problem, optimization algorithms converged to two distinct local solutions with equal minimum weight. Industry will be more inclined to accept the monotonically profiled beam than the odd-shaped design.

The flap design and beam profile calculations represent typical problems of the aerospace industry. Neither problem could be solved satisfactorily without manual intervention. The difficulties encountered to some extent justify the reluctance of the aerospace industry to accept advanced optimization methods, abandoning their time-tested design rules. Neither mathematical programming algorithms nor the traditional design rules could produce optimum hardware configurations that could be manufactured. Their combination, however, was a winner.

\section{IV.(d) Subproblem Solution and Manufacturability}

A nonmanufacturable solution obtained in the subproblem strategy is illustrated considering the design of a cylindrical shell problem, or Problem 6. Solution to the problem was obtained using:

(1) Regular optimization, where the entire structure was considered as a single problem.

(2) Subproblem solution, wherein four overlapping substructures were used.

The optimum profiles for the cylindrical shell obtained using regular and subproblem strategies are depicted in Figure 6. The two optimum weights obtained were $1161.95 \mathrm{lb}$ and 1154.1 $\mathrm{lb}$ for regular and subproblem strategies, respectively. The difference of 0.676 percent in the solutions could be considered negligible especially for the problem complexity. The depth differed substantially between the two solutions. At the crown, the optimum depths of $1.322 \mathrm{in}$. and 2.471 in. obtained by the two methods varied by 53 percent. At the optimum, the regular optimization and the subproblem strategy produced a different number of active constraints. The subproblem strategy produced only active stress constraints, whereas both stress and displacement constraints were active for the regular optimization. The profile obtained using regular optimization was more uniform than that generated through subproblem optimization. To verify the existance of two different designs (one obtained from the subproblem strategy and the other from the regular optimization), we 
resolved the regular optimization case by setting the initial design equal to the optimum solution that was generated from the subproblem strategy. The solution converged to the initial design, confirming the existence of the two local solutions with about the same minimum weight. For this problem the attractiveness of subproblem strategy has been challenged because the design thus obtained is more difficult to manufacture compared to the regular solution. The authors are not aware of a scheme to alleviate this limitation of the subproblem solution strategy.

\section{Discussions}

Discussion is given for multiple design solutions and the convergence of algorithms.

\section{V.1. Multiple Design Solutions}

More than one optimum solution can be obtained for engineering design problems. For example, different solutions were obtained for the nozzle flap, beam profile, cylindrical shell, subsonic aircraft, and engine problems. The values of merit function changed little between the different solutions. The intermediate designs, however, could become nonmanufacturable or their safety could be questioned. These limitations were alleviated through animation and engineering intuition. The utilization of animation improved the design of the nozzle flap, and manipulation of the design bounds promoted the manufacturability of the beam.

Philosophically, we can arrange design methods into a spectrum. Experience occupies the bottom strata. Optimization methods belong to the upper spectrum. Popular design rules occupy the central spectrum. Design improved as we moved from the lower to upper spectrum methods but complexity increased. The design optimization method is in existence for about half a century, yet its full potential has yet to be exploited by industry. The situation can be improved by merging design optimization with the engineering knowledge contained in the broad spectrum methods. This goal can be achieved when proponents of the optimization method and industrial designers work in tandem.

\section{V.2. Convergence of Optimization Algorithms}

Consider the convergence of the subsonic aircraft weight by two different algorithms, shown in Figures 7(a) and 7(b). Convergence was monotonic by both methods even though the rate differed, as expected. A similar trend was observed for the engine problems. Convergence at times oscillated about a mean solution until the maximum iteration limit was reached. Redundancy of the active constraints, their continuity and convexity may have created this situation. Engineering design problems may not satisfy some of the basic requirements that form the foundation of mathematical programming methods. For example, the stress and displacement constraints of structural problems are by nature redundant (ref. 2). The specified range of the constraints of engine and aircraft problems are susceptible to violation during optimization calculations. Optimum solution to multidisciplinary problems of the industry have to be obtained utilizing available analysis and optimization capabilities. The cascade strategy was found successful in generating reliable solutions for structures, aircraft, and engine problems. The cascade strategy was required even when neural network and regression approximators were used to approximate constraints and merit functions of the engineering design problems - this however was not expected. 


\section{Conclusions}

An animation-assisted optimization successfully solved the flap design problem. Cascading of multiple algorithms solved aircraft and engine problems. The beam profile problem was solved through an incorporation of engineering intuition. Generating a regular manufacturable design using a subproblem optimization scheme still remains a challenge. Bringing optimization methods to their rightful industrial environment from the academic plane requires the combined effort of designers and optimization researchers.

\section{REFERENCES}

1. J.D. Guptill, R.M. Coroneos, S.N. Patnaik and L. Berke, "COMETBOARDS User's Manual," NASA TM-4537, 1996.

2. S.N. Patnaik, J.D. Guptill, and L. Berke, "Singularity in Structural Optimization," Int. Jnl. for Numerical Methods in Engrg, vol. 36, 931-944, (1993).

3. S.N. Patnaik, T.M. Lavelle, D.A. Hopkins, and R.M. Coroneos, "Cascade Optimization Strategy for Aircraft and Air-Breathing Propulsion System Concepts," J. Of Aircraft, vol. 34, no. 1, 136-139, (1997).

4. RPK_NASTRAN, COSMIC, University of Georgia, Athens, GA.

5. MSC/NASTRAN Quick Reference Guide, Ver. 68, MacNeal-Schwendler Corporation, 1992.

6. S. Nakazawa: MHOST Version 4.2. Vol. 1: User's Manual. NASA CR-182235-VOL-1, 1989.

7. V. Vance and V.A. Tischler, "ANALYZE-Analysis of Aerospace Structures With Membrane Elements.” Report AFFDL-TR-78-170, Air Force Flight Dynamic Laboratory, Wright-Patterson, AFB, Ohio, (1978).

8. S.N. Patnaik, R.M. Coroneos, and D.A. Hopkins, "Dynamic Animation of Stress Modes via the Integrated Force Method of Structural Analysis," Int. Jnl. of Numerical Methods in Engineering, vol. 40, 2151-2169 (1997).

9. L.A. McCullers, "Aircraft Configuration Optimization Including Optimized Flight Profiles," edited by J. Sobieski, Symposium on Recent Experiences in Multidisciplinary Analysis and Optimization, part 1, NASA CP-2327, 1984.

10. J.L. Klann and C.A. Snyder, “NEPP Programmers Manual,” NASA TM-106575, 1994.

11. W.A. Hafez, "Cometnet-User Manual," IntelliSys, Beachwood, OH, 1996.

12. W. Press, S. Teukolsky, W. Vetterling, and B. Flannery, "Numerical Recipes Example Book (C)," Cambridge University Press, NY, 1987.

13. S.N. Patnaik, J.D. Guptill, D.A. Hopkins, and T.M. Lavelle, "Cascade Optimization for Aircraft Engines with Regression and Neural Network Analysis-Approximators," AIAA JP, in press.

14. S.N. Patnaik, R.M. Coroneos, and D.A. Hopkins, "Substructuring for Structural Optimization in a Parallel Processing Environment," Computer-Aided Civil and Infrastructure Engineering Vol. 15, 209-226 (2000).

15. S.N. Patnaik, A. Gendy, L. Berke, and D.A. Hopkins, "Modified Fully Utilized Design (MFUD) Method for Stress and Displacement Constraints," NASA TM-47431, 1996.

16. G.N. Vanderplaats, "DOT Users Manual," Ver. 2.0. Engineering Design Optimization, Inc., Santa Barbara, CA, 1989. 
17. A. Belegundu, L. Berke, and S.N. Patnaik, "An Optimization Algorithm Based on the Methods of Feasible Directions," Structural Optimization J., vol. 9, 83-88, (1995).

18. G.A. Gabriele and K.M. Ragsdell, "OPT A Nonlinear Programming Code in Fortran Implementing the Generalized Reduced Gradient Method User's Manual," University of Missouri, 1984.

19. L.S. Lasdon and A.D. Waren, "GRG2 User's Guide," University of Texas at Austin, 1986.

20. H. Miura, and L.A. Schmit Jr., "NEWSUMT—A Fortran Program for Inequality Constraint Function Minimization-User's Guide," NASA CR-159070, 1979.

21. J.S. Arora, "IDESIGN User's Manual," Version 3.5.2, Optimal Design Laboratory, University of Iowa, 1989.

22. IMSL MATH/LIBRARY FORTRAN Subroutines for Mathematical Applications, vol. 3, Chapt. 8 , 903, (1987).

23. NAG FORTRAN LIBRARY: MARK 15:E04UCF. NAG Fortran Library Routine Document, vol. 4, (1991).

24. S.N. Patnaik, J.D. Guptill and L. Berke, "Merits and Limitations of Optimality Criteria Methods for Structural Optimization," Int. Jnl. for Numerical Methods in Engineering, vol. 38, 30873120, (1995).

25. A. Belegundu and P.L.N. Murthy, "A New Genetic Algorithm for Multiobjective Optimization," AIAA Paper 96-4180, Sixth AIAA, NASA, and ISSMO Symposium on Multidisciplinary Analysis and Optimization, Bellevue, WA, 1996.

26. S.N. Patnaik, R.M. Coroneos, J.D. Guptill and D.A. Hopkins, "Comparative Evaluation of Different Optimization Algorithms for Structural Design Applications," Int. J. Numer. Methods Eng., vol. 39, 1761-1774, (1996).

27. K.A. Geiselhart, "A Technique for Integrating Engine Cycle and Aircraft Configuration Optimization," NASA CR-191602, 1994.

28. K.A. Geiselhart, M.J. Caddy, and S.J. Morris, Jr. "Computer Program for Estimating Performance of Airbreathing Aircraft Engines," NASA TM-4254, 1991.

29. S.C. Sommer and B.J. Short, "Free-Flight Measurements of Turbulent-Boundary-Layer-Skin Friction in the Presence of Severe Aerodynamic Heating at Mach Number from 2.8 to 7.0," NASA TN-3391, 1955.

30. M.J. Caddy, and S.R. Shapiro, "NEPCOMP-The Navy Engine Performance Computer Program, Version I," NADC-74045-30, Apr. 1975.

31. R.M. Plencner, and C.A. Snyder, "The Navy/NASA Engine Program (NNEP89): a User's Manual," NASA TM-105186, Aug. 1991.

32. S.N. Patnaik, R.M. Coroneos, and D.A. Hopkins, "Compatibility Conditions of Structural Mechanics," Int. Jnl. of Numerical Methods in Engineering, vol. 47, 685-704 (2000). 
TABLE I: Solution to the subsonic aircraft design problem using a cascade strategy

\begin{tabular}{|c|c|c|c|}
\hline & $\begin{array}{l}\text { Cascade solution } \\
\text { (Optimizer } 1-2-3 \text { ) } \\
\text { Optimum design }\end{array}$ & $\begin{array}{l}\text { Optimizer } 1 \text { solution } \\
\text { (as percent of } \\
\text { cascade solution) } \\
\text { Infeasible and heavy }\end{array}$ & $\begin{array}{l}\text { Optimizer } 2 \text { solution } \\
\text { (as percent of } \\
\text { cascade solution) } \\
\text { Feasible but heavy }\end{array}$ \\
\hline Weight, $\mathrm{lb}$ & 199818.00 & 1.01 & 1.02 \\
\hline \multicolumn{4}{|l|}{ Design variables } \\
\hline Wing aspect ratio (from 5 to 12 ) & 8.33 & 0.94 & 1.19 \\
\hline Engine thrust, lb (from 20000 to $70000 \mathrm{lb}$ ) & 31228.21 & .94 & .99 \\
\hline Wing area, $\mathrm{ft}^{2}$ (from 1000 to $3000 \mathrm{ft}^{2}$ ) & 1936.05 & 1.04 & 1.00 \\
\hline Quarter-chord sweep angle of the wing, deg (from $0^{\circ}$ to $45^{\circ}$ ) & 11.63 & .93 & 2.32 \\
\hline Wing thickness to chord ratio (from 0.05 to 0.15 ) & .09 & .89 & 1.22 \\
\hline Engine design point turbine entry temperature, ${ }^{\circ} \mathrm{R}$ & 3014.29 & .93 & .94 \\
\hline Overall pressure ratio (from 10 to 40 ) & 39.12 & .83 & .86 \\
\hline Bypass ratio (from 0.1 to 15.0 ) & 5.65 & 61 & .68 \\
\hline Fan pressure ratio (from 1.1 to 3.5 ) & 1.83 & 1.16 & 1.14 \\
\hline \multicolumn{4}{|l|}{ Constraints } \\
\hline Approach velocity, kn (not to exceed 125 kn) & 118.75 & 0.98 & 1.0 \\
\hline Takeoff field length, ft (not to exceed $6000 \mathrm{ft}$ ) & 6000.00 & a 6282.00 & ${ }^{\mathrm{a}} 6000.00$ \\
\hline Landing field length, $\mathrm{ft}$ (not to exceed $6000 \mathrm{ft}$ ) & 5460.00 & .98 & 1.0 \\
\hline Mixed approach thrust, $\mathrm{lb}$ (normalized with respect to $100000 \mathrm{lb}$ ) & 97000.00 & 1.02 & 1.0 \\
\hline Second segment climb, lb (thrust normalized with respect to $100000 \mathrm{lb}$ ) & 93000.00 & 1.03 & .98 \\
\hline Compressor discharge temperature, ${ }^{\circ} \mathrm{R}$ & 1416.20 & .93 & .95 \\
\hline Excess fuel, gal (normalized with respect to 5000 gal) & 5000.00 & a 2150.00 & a 8150.00 \\
\hline
\end{tabular}

${ }^{\mathrm{a}}$ Actual values.

TABLE II: Intermediate and final solutions for the beam profile

\begin{tabular}{|c|c|c|c|c|}
\hline \multicolumn{5}{|c|}{$\begin{array}{l}\text { Intermediate solution } \\
\text { [Only the stress constraint at the root was active.] }\end{array}$} \\
\hline $\begin{array}{l}\text { Design } \\
\text { variable }\end{array}$ & $\begin{array}{l}\text { Lower } \\
\text { bound }\end{array}$ & $\begin{array}{l}\text { Initial } \\
\text { design }\end{array}$ & $\begin{array}{l}\text { Upper } \\
\text { bound }\end{array}$ & $\begin{array}{l}\text { Optimum } \\
\text { design }\end{array}$ \\
\hline 1 & 0.5 & 10.0 & 15.0 & 14.68 \\
\hline 2 & & & & 2.98 \\
\hline 3 & & & & 5.04 \\
\hline 4 & & & & 6.27 \\
\hline 5 & & & & 5.41 \\
\hline 6 & & & & .50 \\
\hline 7 & & & & 2.49 \\
\hline 8 & & & & 2.67 \\
\hline 9 & & & & 5.14 \\
\hline
\end{tabular}

\begin{tabular}{|c|c|c|c|c|}
\hline \multicolumn{5}{|c|}{ Final solution } \\
[Tip displacement and root stress were the active constraints.] \\
\hline $\begin{array}{c}\text { Design } \\
\text { variable }\end{array}$ & $\begin{array}{c}\text { Lower } \\
\text { bound }\end{array}$ & $\begin{array}{c}\text { Initial } \\
\text { design }\end{array}$ & $\begin{array}{c}\text { Upper } \\
\text { bound }\end{array}$ & $\begin{array}{c}\text { Optimum } \\
\text { design }\end{array}$ \\
\hline 1 & 10.0 & 12.0 & 13.0 & 11.72 \\
2 & 9.0 & 8.0 & 12.0 & 9.00 \\
3 & 6.0 & 7.0 & 10.0 & 6.22 \\
4 & 5.0 & 6.0 & 9.0 & 6.17 \\
5 & 4.0 & 5.0 & 8.0 & 5.02 \\
6 & 3.0 & 4.0 & 7.0 & 3.67 \\
7 & 2.0 & 3.0 & 6.0 & 2.00 \\
8 & 1.0 & 2.0 & 5.0 & 1.32 \\
9 & .5 & 1.0 & 4.0 & .50 \\
\hline
\end{tabular}




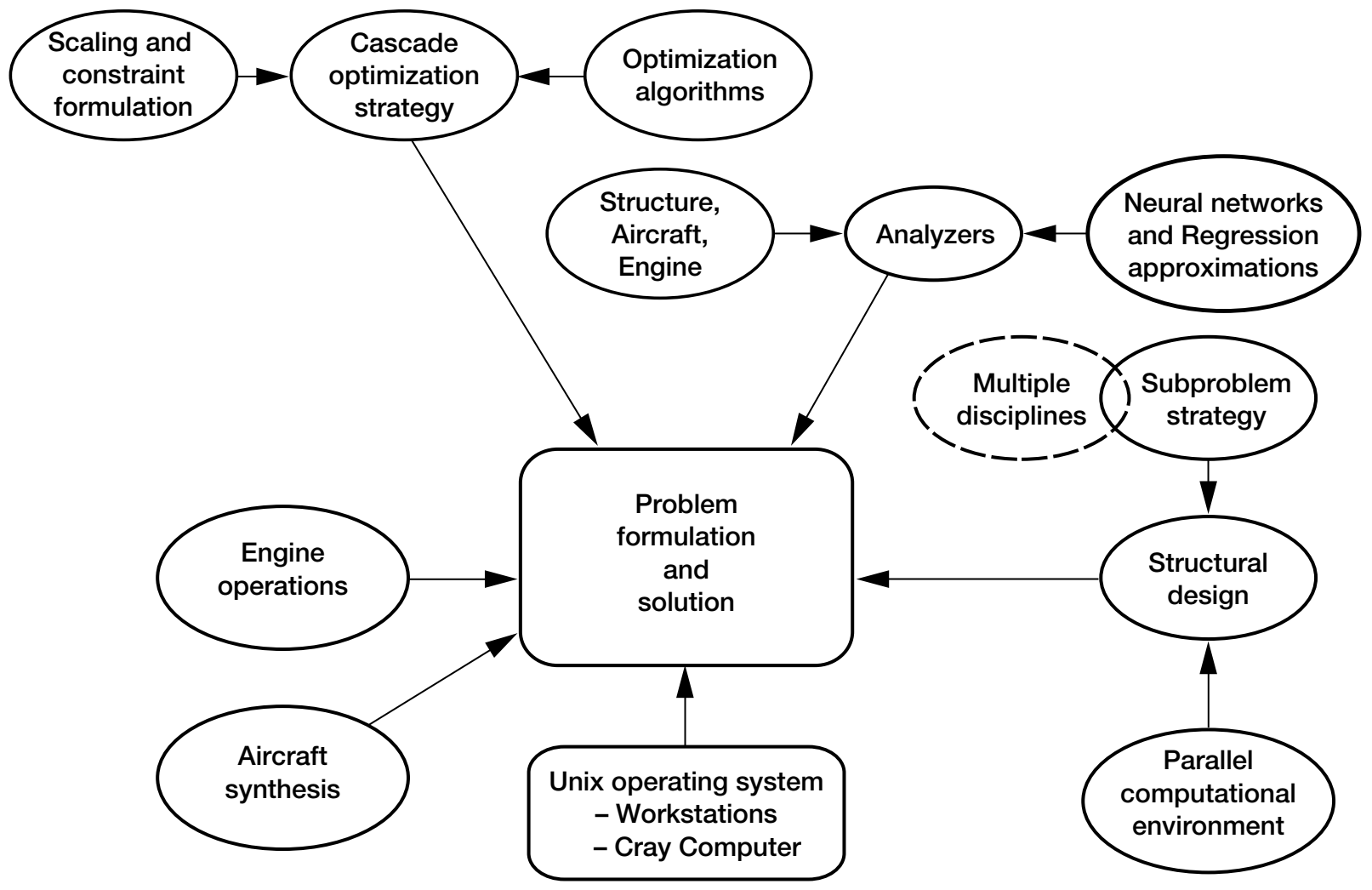

Figure 1.-Organization of the multidisciplinary design optimization testbed COMETBOARDS. 


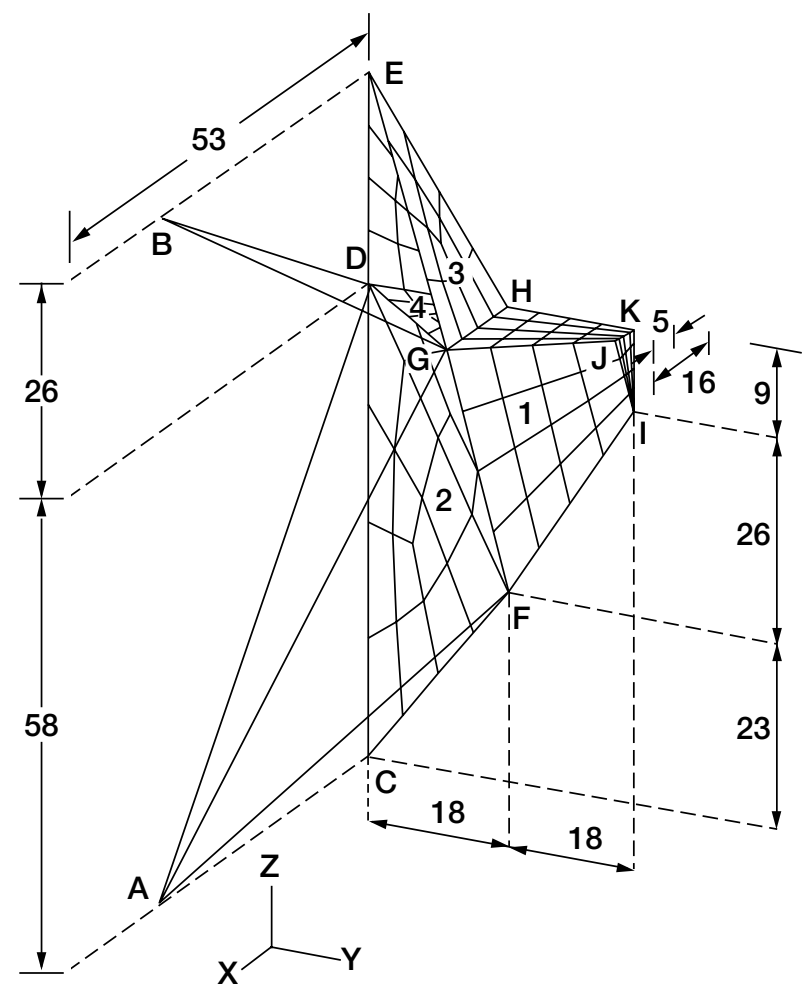

Figure 2.-Cargo-bay support system of the International Space Station. Dimensions are in inches. 


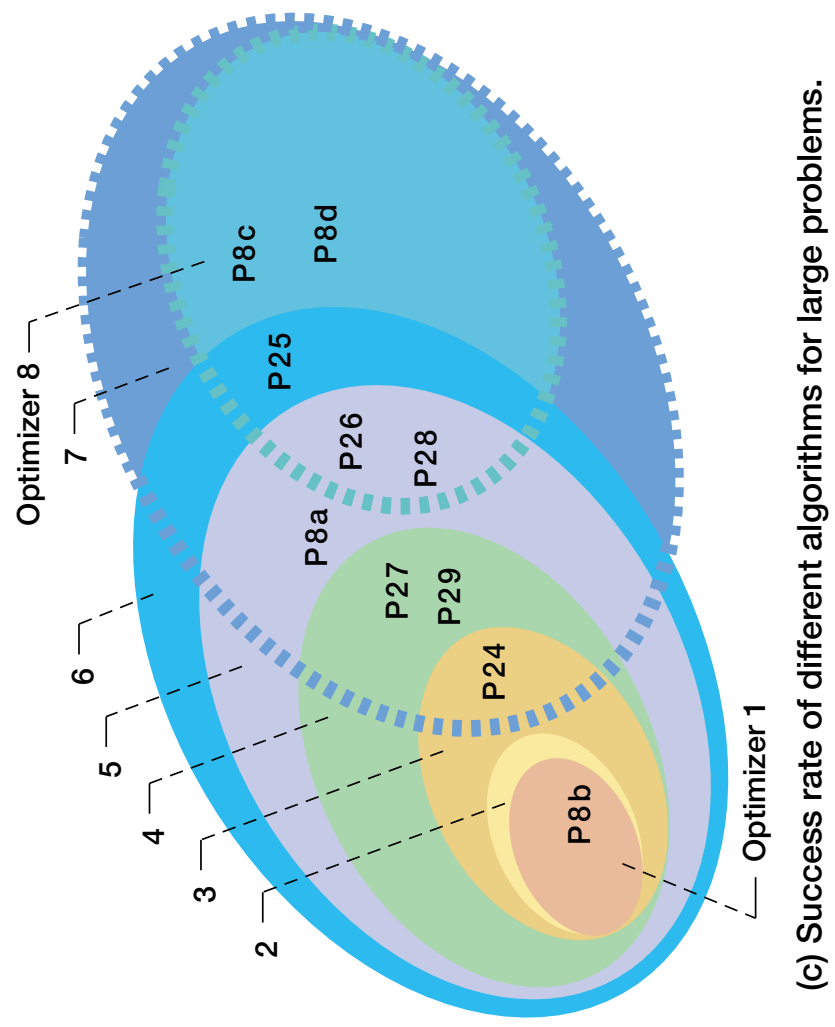

Ф্

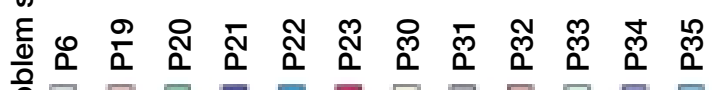
음

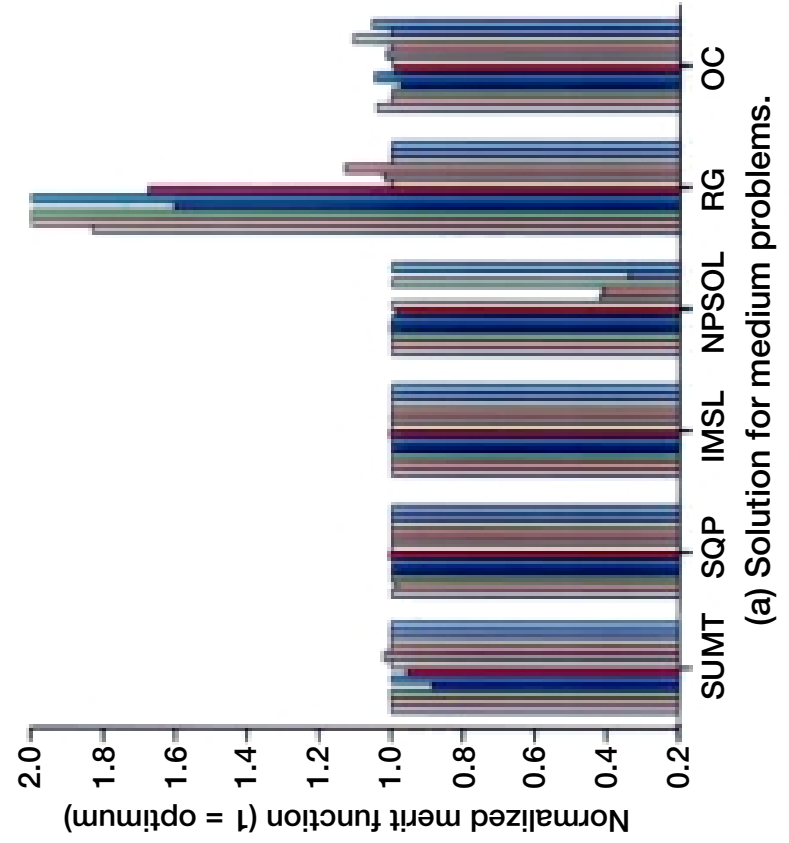

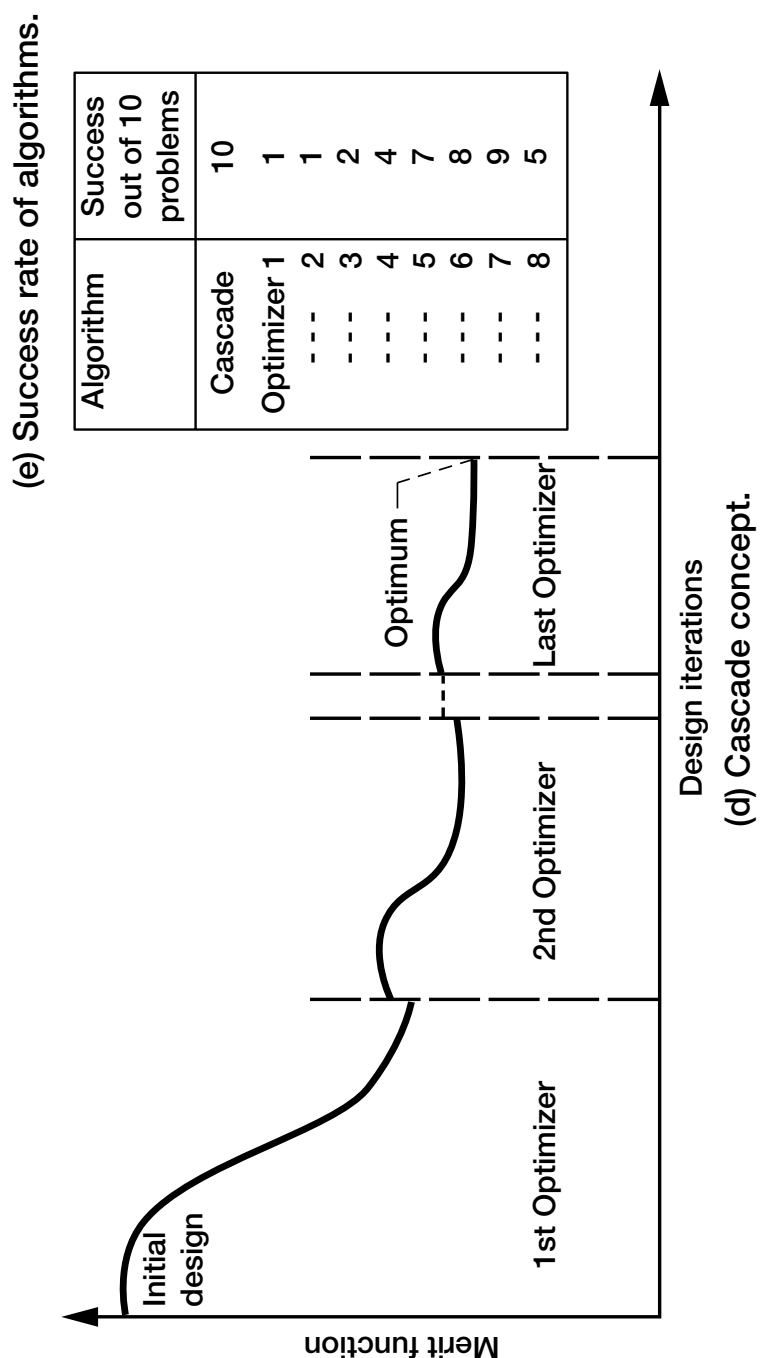

Ф

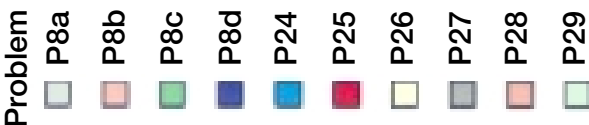

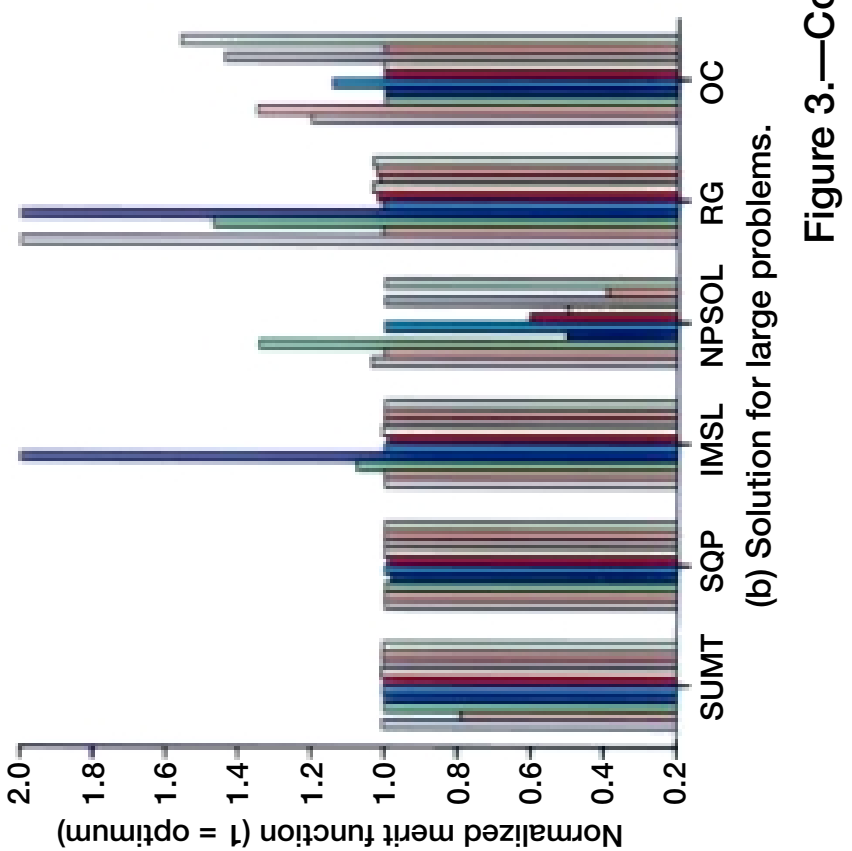



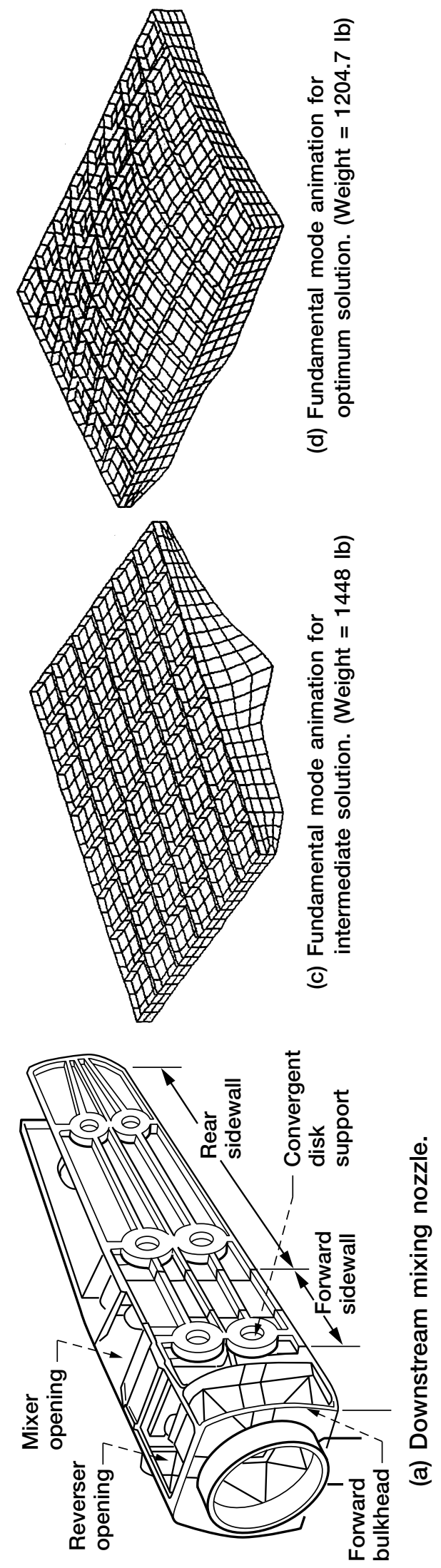
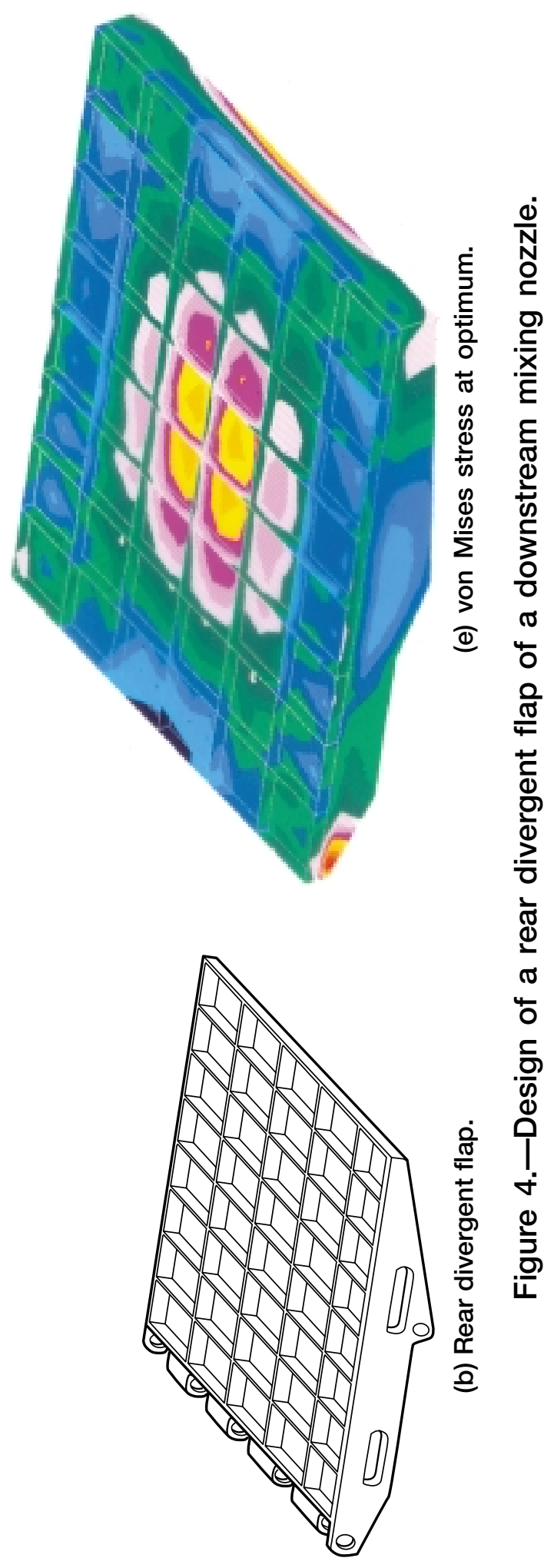


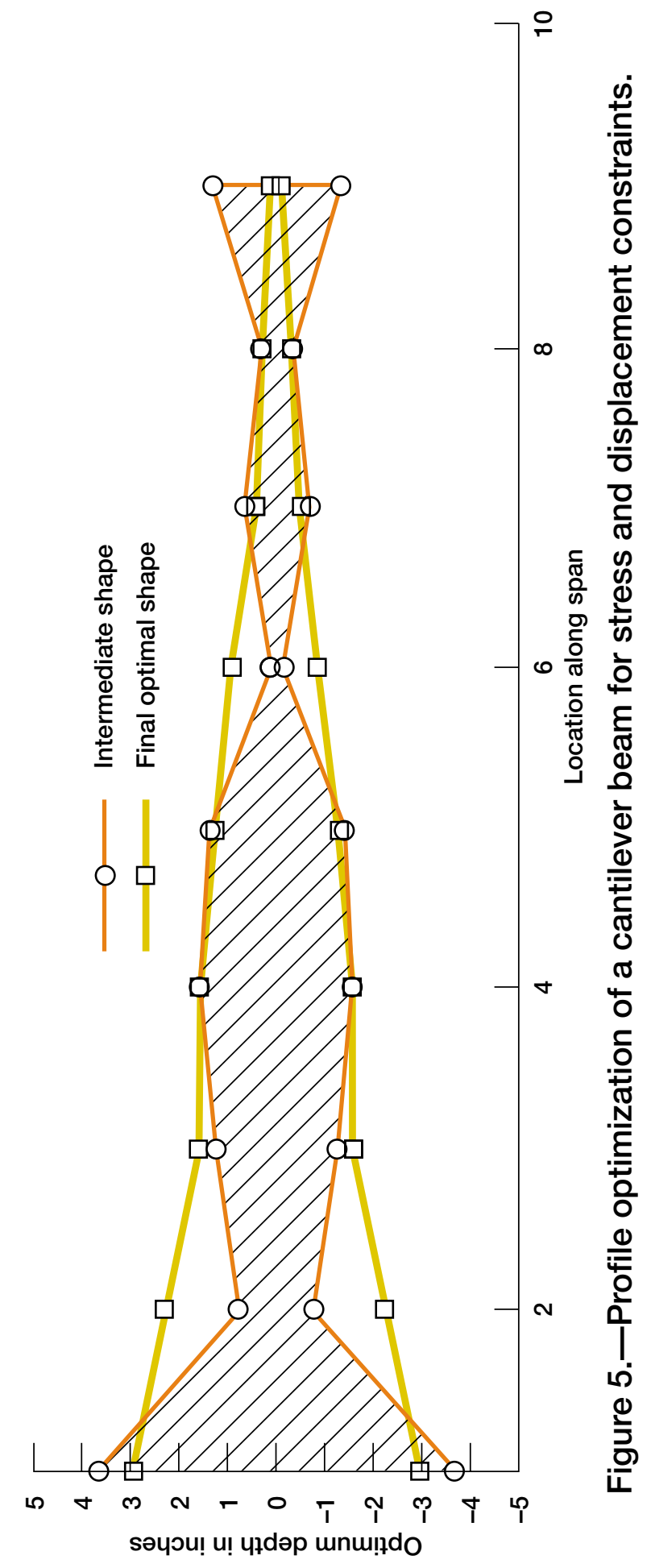




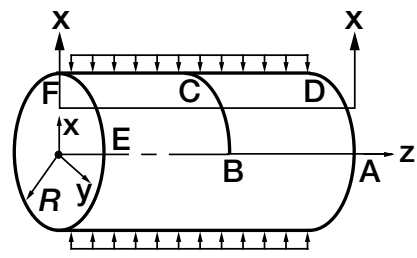

(a) Cylindrical shell.

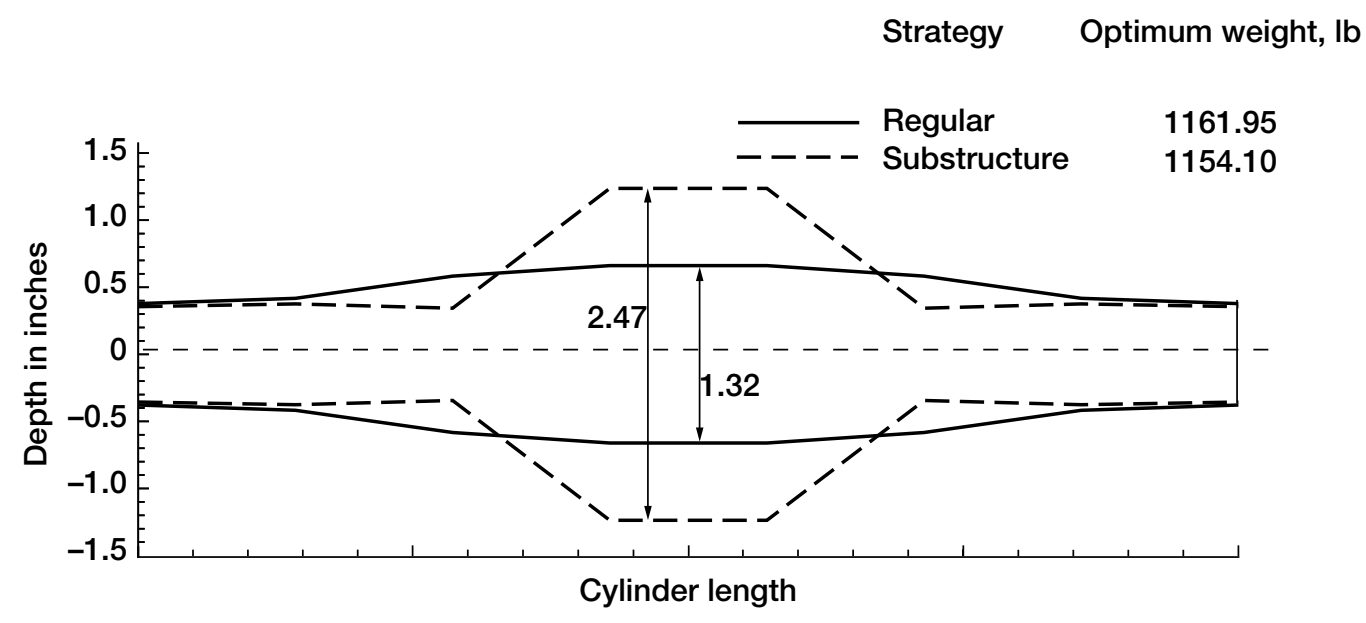

(b) Optimum profile along cylinder length.

Figure 6.-Substructure optimization of a cylindrical shell. 

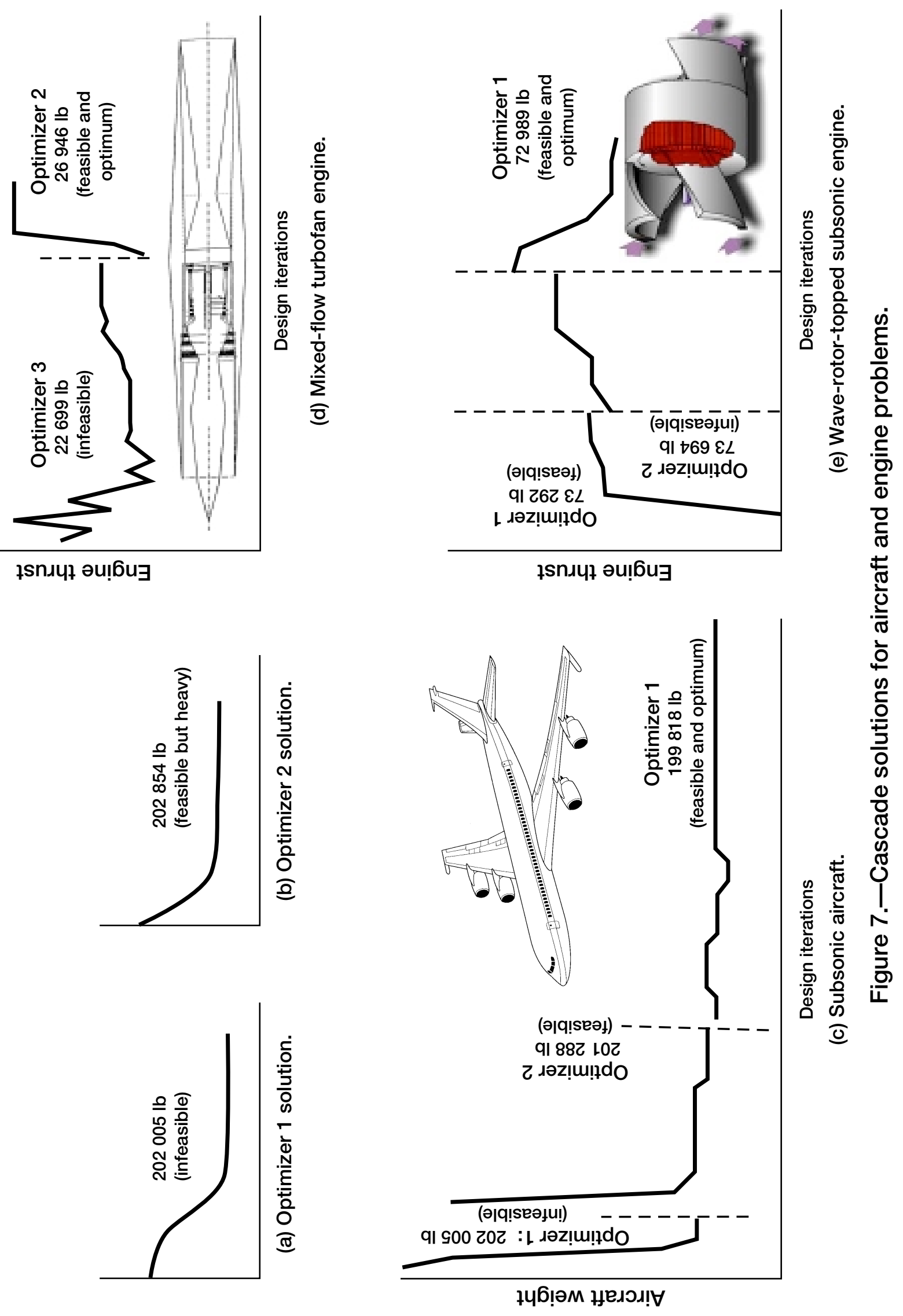
Public reporting burden for this collection of information is estimated to average 1 hour per response, including the time for reviewing instructions, searching existing data sources, gathering and maintaining the data needed, and completing and reviewing the collection of information. Send comments regarding this burden estimate or any other aspect of this collection of information, including suggestions for reducing this burden, to Washington Headquarters Services, Directorate for Information Operations and Reports, 1215 Jefferson Davis Highway, Suite 1204, Arlington, VA 22202-4302, and to the Office of Management and Budget, Paperwork Reduction Project (0704-0188), Washington, DC 20503.

\begin{tabular}{|l|l|l}
\hline 1. AGENCY USE ONLY (Leave blank) & $\begin{array}{c}\text { 2. REPORT DATE } \\
\text { August } 2000\end{array}$ & $\begin{array}{r}\text { 3. REPORT TYPE AND DATES COVERED } \\
\text { Technical Memorandum }\end{array}$ \\
\hline
\end{tabular}

\section{TITLE AND SUBTITLE}

5. FUNDING NUMBERS

Lessons Learned During Solutions of Multidisciplinary Design

Optimization Problems

\section{AUTHOR(S)}

Surya N. Patnaik, Rula M. Coroneos, Dale A. Hopkins, and Thomas M. Lavelle

WU-714-04-50-00

NCC3-738

8. PERFORMING ORGANIZATION REPORT NUMBER

E-11992

National Aeronautics and Space Administration

John H. Glenn Research Center at Lewis Field

Cleveland, Ohio 44135-3191

10. SPONSORING/MONITORING AGENCY REPORT NUMBER

National Aeronautics and Space Administration

Washington, DC 20546-0001

NASA TM-2000-210363

\section{SUPPLEMENTARY NOTES}

Surya N. Patnaik, Ohio Aerospace Institute, 22800 Cedar Point Road, Brook Park, Ohio 44142, (work funded by NASA Cooperative Agreement NCC3-738); and Rula M. Coroneos, Dale A. Hopkins, and Thomas M. Lavelle, NASA Glenn Research Center. Responsible person, Dale A. Hopkins, organization code 5930, (216) 433-3260.

12a. DISTRIBUTION/AVAILABILITY STATEMENT

12b. DISTRIBUTION CODE

Unclassified - Unlimited

Subject Category: 39

Distribution: Nonstandard

This publication is available from the NASA Center for AeroSpace Information, (301) 621-0390.

\section{ABSTRACT (Maximum 200 words)}

Optimization research at NASA Glenn Research Center has addressed the design of structures, aircraft and airbreathing propulsion engines. During solution of the multidisciplinary problems several issues were encountered. This paper lists four issues and discusses the strategies adapted for their resolution. (a) The optimization process can lead to an inefficient local solution. This deficiency was encountered during design of an engine component. The limitation was overcome through an augmentation of animation into optimization. (b) Optimum solutions obtained were infeasible for aircraft and air-breathing propulsion engine problems. Alleviation of this deficiency required a cascading of multiple algorithms. (c) Profile optimization of a beam produced an irregular shape. Engineering intuition restored the regular shape for the beam. (d) The solution obtained for a cylindrical shell by a subproblem strategy converged to a design that can be difficult to manufacture. Resolution of this issue remains a challenge. The issues and resolutions are illustrated through six problems: (1) design of an engine component, (2) synthesis of a subsonic aircraft, (3) operation optimization of a supersonic engine, (4) design of a wave-rotor-topping device, (5) profile optimization of a cantilever beam, and (6) design of a cylindrical shell. The combined effort of designers and researchers can bring the optimization method from academia to industry.

\section{SUBJECT TERMS}

Algorithms; COMETBOARDS; Multidisciplinary; Optimization; Structures; Subsonic aircraft; Supersonic engine; Wave rotor

\begin{tabular}{|c|c|c|}
\hline $\begin{array}{c}\text { 17. SECURITY CLASSIFICATION } \\
\text { OF REPORT } \\
\text { Unclassified }\end{array}$ & $\begin{array}{c}\text { 18. SECURITY CLASSIFICATION } \\
\text { OF THIS PAGE } \\
\text { Unclassified }\end{array}$ & $\begin{array}{c}\text { 19. SECURITY CLASSIFICATION } \\
\text { OF ABSTRACT } \\
\text { Unclassified }\end{array}$ \\
\hline
\end{tabular}

